TITLE:

\title{
Application of the modified feed formulation to optimize economic and environmental criteria in beef cattle fattening systems with food by-products
}

\section{$\operatorname{AUTHOR}(\mathrm{S}):$}

Oishi, Kazato; Kumagai, Hajime; Hirooka, Hiroyuki

\section{CITATION:}

Oishi, Kazato ...[et al]. Application of the modified feed formulation to optimize economic and environmental criteria in beef cattle fattening systems with food by-products. Animal Feed Science and Technology 2011, 165(1-2): 38-50

\section{ISSUE DATE:}

2011-04

URL:

http://hdl.handle.net/2433/139742

\section{RIGHT:}

(c) 2011 Elsevier B.V.; この論文は出版社版でありません。引用の際には 出版社版をご確認ご利用ください。; This is not the published version. Please cite only the published version. 
Application of the modified feed formulation to optimize economic and

environmental criteria in beef catte fattening systems with food

by-products

4

5 Kazato OISHI, Hajime KUMAGAI, Hiroyuki HIROOKA

Laboratory of Animal Husbandry Resources, Division of Applied

Biosciences, Graduate School of Agriculture, Kyoto University, Sakyo-ku,

8 Kyoto 606-8502, Japan

9

$10 \quad$ E-mail:

11 Kazato OISHI:kazato@kais.kyoto-u.ac.jp

12 HajimeKUMAGAI:hkuma@kais.kyoto-u.ac.jp

13 Hiroyuki HIROOKA: hirooka@kais.kyoto-u.ac.jp

14

15

Corresponding author: Kazato OISHI

Tel \& Fax: 81 ( 0$)$ 75-753-6365

18

E-mail:kazato@kais.kyoto-u.ac.jp

19 Kitasirakawa-Oiwake-Cho, Sakyo-ku, Kyoto 606-8502, Japan 
Abstract A simplified ration optimization method was applied to a beef cattle fattening system to evaluate the utilization of food by-products under various situations. The method was extended to reduce feed costs (i.e., economic factors) and nitrogen and phosphorus excretions (i.e., environmental factors) by introducing penalty coefficients of nitrogen and phosphorus contents in each ingredient of the diet in the objective function in traditional linear programming. Six regional food by-products,

8 five commercial concentrates and two roughages were used as ingredients

9 of the fermented total mixed ration. Constraints for the feed formulation were based mainly on nutrient requirements in the Japanese Feeding

11 Standard for Beef Cattle. The replacement price (or acquisition cost) of

12 food by-products was defined as the maximum price of food by-products

13 when the feed cost with the use of food by-products was below the cost

14 with the use of conventional concentrates. The results showed that

15 although the replacement prices were not greatly affected by the penalty

16 levels, they were associated with the changes in the substitution rate of

17 food by-products for concentrates and the price of concentrates. The

18 replacement prices were about 16 (yen/kg, as-fed basis) against the

19 present price level of concentrates, when food by-products were

20 substituted for a half of concentrates. Feed compositions were altered and

21 nitrogen and phosphorus excretions were decreased by the changes of

22 penalties, in spite of the small change in the replacement price of food

23 by-products. Both nitrogen and phosphorus penalties greatly reduced the

24 nitrogen and phosphorus excretions, indicating that nitrogen and

25 phosphorus penalty coefficients should be introduced together in the 
1 objective function in order to reduce both excretions efficiently.

2 Keywords: beef cattle; excretion; feed formulation; food by-products;

3 nitrogen and phosphorus penalties

4 Abbreviations: ADF, acid detergent fiber; CP, crude protein; DIP, 5 degradable intake protein; DM, dry matter; EE, ether extract; MINAS, 6 Mineral Accounting System; NDF, neutral detergent fiber; RR, ratio of 7 roughage to the total feed amount on a DM basis; TDN, total digestible 8 nutrients; TMR, total mixed ration; VA, vitamin A

9 


\section{Introduction}

2

Due to economic and environmental concerns, the feasibility of using by-products as animal feeds has been examined in many regions of both developing and developed countries. In developing countries, better utilization of non-conventional feed resources (food by-products) which do not compete with human nutrition is imperative in order to meet the projected high demand of livestock products (Maghsoud et al., 2008). In developed countries, low-cost waste management programs that involve feeding by-products from crop- and food-processing industries to farm animals have become very important in recent years (Bampidis and Robinson, 2006). As in Japan, utilization of food by-products has been strongly promoted for raising the self-sufficiency rate of feeds (Sugiura et al., 20009$)$.

Available food by-products, or so-called Ecofeed (Economical and ecological feed resources) in Japan, include beverage wastes such as brewer's grain, distiller's grain, fruit juice pomace and tea waste, food manufacturing wastes such as soybean curd residue (tofu waste), soy sauce cake and blackstrap molasses, vegetable wastes, bakery and noodle wastes and disposals from food service industries. These food by-products usually have high energy and/or protein contents, which can provide competitive alternatives to more traditional energy or protein sources (Westendorf, 2000 ). Replacing imported commercial feeds with food by-products can save energy in transportation and reduce the environmental impact of burning or landfilling food wastes (Cao et al., 
$12009)$. Nonetheless, despite the vast potential of by-products as a constituent of farm animal diets, the degree of usage is dependent on the economic value of the by-products and the market prices of conventional feedstuffs (Harpster, 2000 ).

In recent years, environmental pollution caused by high levels of animal waste has become one of the major concerns regarding intensive animal production systems in many countries. Excess nitrogen and phosphorus excretion from feces and urine of farm animals can lead to several environmental problems. For instance, nitrogen contributes to environmental pollution in two ways, as ammonia in the air or as nitrate in soil and ground water, and a high level of phosphorus excretion leads to leakage into surface and ground waters (Tamminga, 1992). In particular, $\mathrm{N}_{2} \mathrm{O}$ derived from nitrogen in cattle waste contributes to global warming in the process of Japanese beef production systems (Ogino et al. 2004, 2007), and the reduction in nitrogen excretion from beef production is strongly expected to meet the Kyoto Protocol in Japan.

Linear programming is certainly the most popular method for diet formulation (Brokken, 1971; Crabtree, 1982; Kikuhara et al., 2009; Tedeschi et al., 2000 ; Tozer, 2000$)$. The ordinal linear programming method enables the formulation of least-cost diets that satisfy specific nutrient requirements, but it cannot consider the effects of excess nitrogen and phosphorus contents in the diets on the excretions of these substances into soil and ground water. To solve this problem, Jean dit Bailleul et al. (2001) and Pomar et al. (2007) modified the ordinal least-cost feed formulation to simultaneously minimize feed cost and 
1 excess nitrogen and phosphorus, respectively, and then applied it to the

2 actual formulation of feed for pig production. Hirooka and Oishi (2010)

3 used the same method to minimize feed cost and nitrogen excretion when

4 whole crop rice silage was utilized as a feed for beef cattle feedlot

5 production in Japan.

6 The objective of this study was, therefore, to evaluate the economic and environmental impact of the use of food by-products as animal feeds on

8 the Japanese beef fattening system by using the modified least-cost feed 9 formulation method.

\section{Materials and methods}

\subsection{Overview of the simulation}

It was assumed in this study that the beef fattening system for Japanese Black (Wagyu) steers starts from the purchase of calves with a body weight of $285 \mathrm{~kg}$ (initial weight) at calf markets and culminates with slaughter at a final weight of $714 \mathrm{~kg}$. The fattening period was equally divided into three parts: early, middle and late. The daily gain in each period was estimated from the given average daily gain (0.7kg/day) for

20 the whole fattening period using the Gompertz growth curve function with

21 the estimated mature weight $(748 \mathrm{~kg})$. Details of the calculation are

22 shown in the Appendix. Daily nutrient requirements were calculated from

23 the estimated daily gain and body weight in accordance with the Japanese

24 Feeding Standard for Beef Cattle (NARO, 2008). The daily nutrients were summed up for each fattening period, and the modified least-cost feed 
1 formulation was then conducted for the constraints for nutrient

\subsection{Feed ingredients and constrained conditions}

Fig. 1 shows outline of the system of feed formulation with food by-products in this study. Six regional food by-products (brewer's grain (wet), soybean curd residue (wet), soy sauce cake (wet), blackstrap molasses, udon noodle waste and green tea waste), five commercial concentrates (corn, barley, soybean meal, wheat bran and calcium carbonate) and two roughages (hay and rice straw) were used as ingredients of the fermented total mixed ration (TMR) in this study (Table 1). Concentrate and roughage ingredients were selected as the standard imported feeds in the Japanese beef fattening system (Ogino et al., 2004), and the chemical composition of feeds was based mainly on the Standard Tables of Feed Composition in Japan (NARO, 2009). One milligram of beta-carotene was converted into 400 IU of vitamin A.

Requirements for the following nutrients on an as-fed basis were set as the constraints of the feed formulation: dry matter (DM; kg/period), crude protein (CP; kg/period), total digestible nutrients (TDN; kg/period), neutral detergent fiber (NDF; kg/period), acid detergent fiber (ADF; kg/period), calcium (Ca; kg/period), phosphorus (P; kg/period), degradable intake protein (DIP; kg/period), ether extract (EE; kg/period) and vitamin A (VA; IU/period). Margins of $10 \%$ were added to the nutrient 
requirements of DM, CP, TDN and DIP for safety based on the Japanese Feeding Standard for Beef Cattle (NARO, 2008 ). The lower bounds of the feeding amounts for NDF and ADF were set to be 160 and 100 (g/kg, DM basis), respectively. The effectiveness of fiber in food by-products to

5 stimulate chewing activity and ruminal function was set to be 0.4 (40\%) of that of roughages based on the report of Swain and Armentano (1994). In order to avoid the incidence of urolithiasis, the lower and upper bounds of the ratio of Ca to $\mathrm{P}$ ( $\mathrm{Ca} / \mathrm{P}$ ) were set to be 1.5 and 2 , respectively. The upper bound of EE was assumed to be 60 (g/kg, DM basis). The range between the lower and upper bounds of VA in each period was set to be 3000 IU/day, and the lower limits of VA were set to be the value of the VA requirement for the early period but fixed to lower values for the middle and late periods (3000IU/day and 5000IU/day, respectively), because, in Japan, the VA supply in the middle and late fattening periods of beef production is generally restricted in order to generate a high degree of marbling (Oka et al., 1998). The upper bound for the water content of formulated feeds was set to be 650 (g/kg, as fed basis), since this study assumed the feed formulation for fermented TMR without control of moisture content by drying.

In addition to the above constraints for nutrients, some feed supplies were constrained. The ratio of roughage to the total feed amount on a DM

22 basis ( $R R$ ) was constrained by the following quadratic function estimated

23 from the data of Ogino et al. (2004):

$24 \quad R R \geq 1.211-0.003459 \times W(t)+0.000002727 \times W(t)^{2}$

25 where $W(t)$ is the weight of the animal at age $t$ (days). The upper bound 
1 for the ratio of the feeding amount of wheat bran to concentrates was set

2 to $25(\mathrm{~kg} / \mathrm{kg})$ on an as-fed basis. Furthermore, with respect to food

3 by-products, because soy sauce cake was assumed to include 80 (g/kg,

4 as-fed basis) of $\mathrm{NaCl}$, the upper bound for $\mathrm{NaCl}$ in the soy sauce cake was

5 set to be 10 (g/kg, DM). The upper bounds for green tea waste and

6

8

9

10

11

12

13

14

15

16

\subsection{Feed price}

In the base simulation, the prices of imported roughages and concentrates were assumed to be the average prices of the roughages and concentrates from 2000 to 2008 (MAFF, 2006; MAFF, 2010). Because of lack of price information on food by-products, prices of food by-products including the costs of transportation and preservation were assumed to be identical and variable from 1 to 30 (yen/kg, as-fed basis).

\subsection{Modified feed formulation method}

Since the simulation in this study aimed at reducing not only the feed cost but also the nitrogen and phosphorus excretions, least-cost ration formulations were executed by an optimization method in which the penalties for high nitrogen and/or phosphorus content feeds were included. The method was based on the following modified linear programming formulae:

$$
C=\sum\left(c_{i}+\beta_{N} N_{i}+\beta_{P} P_{i}\right) x_{i}
$$

$$
\boldsymbol{A} \boldsymbol{X} \geqq,=\text {, or } \leqq \boldsymbol{B}
$$




$$
\boldsymbol{X} \geqq \mathbf{0},
$$

2 where $c_{i}$ is the cost of the $i$ th ingredient, $\beta_{N}$ and $\beta_{P}$ are the weight

3 coefficients representing the assumed costs associated with nitrogen and

4 phosphorus contents, $N_{i}$ and $P_{i}$ are the amounts of nitrogen (CP/6.25)

5 and phosphorus in the $i$ th ingredient, $x_{i}$ is the amount of the $i$ th

6 ingredient in the vector $\boldsymbol{X}$ and $C$ is the ingredient mix costs including

7 the environmental costs per unit weight (yen/period). In addition, $\boldsymbol{A}$ is

8 the coefficient matrix of the system, where each $a_{i j}$ represents the

9 amount of nutrient or constrained value $j$ in the $i$ th ingredient and $\boldsymbol{B}$

10 is the vector of nutrient requirements and constraints (Table 2 ). The

11 method used to calculate the constrained values for each ingredient is

12 shown in the Appendix. The weight constants $\beta_{N}$ and $\beta_{P}$ are assumed to

13 be the penalty costs for nitrogen and phosphorus excretions in the

14 objective functions. The amount of nitrogen excretion was calculated as

15 the difference between nitrogen intake and retained nitrogen based on the

16 Japanese Feeding Standard for Beef Cattle (NARO, 2008). In a similar

17 fashion, the amount of phosphorus excretion was calculated based on NRC

18 (2000). The penalty costs were used only for reducing excretions and were

19 not included in total feed cost; hence, the total feed cost was calculated 20 as $\sum c_{i} x_{i}$.

\subsection{Simulated scenarios}

One of the aims of this study was to estimate the replacement price of

24 food by-products. In this study, the replacement price of food by-products

25 was defined as the maximum price of food by-products in the case where 
1 the feed cost with the use of food by-products was below the cost without

2 the use of food by-products. The price can be estimated by comparing the

3 least-cost feed formulation results with and without the use of food

4 by-products. Under this approach, the effect of the change in the penalty

5 costs for nitrogen and phosphorus excretions on the simulated result was

6 also examined. In addition, the effects of the change in the substitution

7 rate of food by-products for concentrates (kg/kg, as-fed basis) and the

8 change in prices of concentrates were analyzed.

9 Table 3 shows the simulation parameters for the base simulation and the 10 alternatives. The weights for nitrogen and phosphorus penalties were 11 assumed to be 2.30 and 3.92 (euro/kg) (276.0 and 470.4 (yen/kg) assuming 12120 yen $=1$ euro) based on levies for nitrogen and phosphorus excretions 13 by the Mineral Accounting System (MINAS) in the Netherlands 14 (Hanegraaf and den Boer, 2003). Three penalty levels for nitrogen and 15 phosphorus excretions (no penalty; a penalty identical to that in MINAS 16 (penalty $x 1$ condition); and a penalty twice that in MINAS (penalty 2 condition)), three substitution rates of food by-products (0.50 for the 18 base, 0.25 for the low substitution rate and 0.75 for the high substitution 19 rate), and three price levels of concentrates were assumed.

\section{3. Results}

3.1.Effects of nitrogen and phosphorus penalties on the replacement price of food by-products

Fig. 2 shows the differences between the total feed costs with and 
without the use of food by-products under three nitrogen and phosphorus

2 penalty conditions under various prices of food by-products. The replacement price of food by-products was 17 (yen/kg) under the no penalty and penalty $x 1$ conditions, and 16 (yen/kg) under the penalty x 2 condition. This result showed that the effect of penalty levels for nitrogen and phosphorus excretions on the replacement prices of food by-products was relatively small. The differences in total feed costs between the case with and without the use of food by-products decreased linearly with an increase in price of food by-products under all penalty conditions.

3.2.Differences in nitrogen and phosphorus excretions with and without the use of food by-products

The differences in nitrogen and phosphorus excretions with and without the use of food by-products are shown in Fig. 3. Nitrogen excretion was increased by the use of food by-products under all penalty conditions, although the difference in nitrogen excretion decreased with an increase in the penalty levels. In contrast, phosphorus excretion was decreased with the use of food by-products under all penalty conditions and the rate of decrease was increased in keeping with the penalty levels.

\subsection{Optimal ration formulation under the three penalty levels}

Table 4 shows the simulated results of feed compositions, feed costs and nitrogen and phosphorus excretions for each fattening period under the three penalty conditions. Feed costs in the total fattening period 
1 increased consistently with the penalty levels, but the differences among the three penalty levels were small. However, nitrogen and phosphorus excretions in each period and also in the total fattening period decreased markedly with an increase in the penalty levels. The decreases in nitrogen and phosphorus excretions with increasing penalty levels resulted from the differences between feed compositions under the three penalty levels.

When no penalties were introduced, soybean curd residue was selected as the main feed resource. When the penalty was introduced, however, the composition of food by-products was strongly affected; the proportion of soybean curd residue strongly decreased but that of udon noodle waste increased in keeping with the penalty levels. Brewer's grain was not selected as a food by-product ingredient in the optimal ration under any of the penalty conditions. Green tea waste was selected instead of hay as a resource of VA in the early period, but VA restrictions in the middle and later period were too severe to allow the use of green tea waste and hay as feeds. The composition of concentrates was also affected by the change in the penalty levels; enhanced penalty levels increased the proportions of barley but decreased that of wheat bran.

3.4.Effects of various nitrogen and/or phosphorus penalty levels on feed costs and excretions

The effects of various nitrogen and/or phosphorus penalty levels on feed costs with the use of food by-products are presented in Fig. 4. The feed costs increased consistently with the penalty levels of nitrogen and phosphorus excretions, but the range of the rates of increase was small 
1 ( $0-2.5 \%)$. In contrast, changes in the penalty levels of nitrogen and

2 phosphorus excretions led to large reductions of nitrogen and phosphorus

3 excretions (Fig. 5). It was noteworthy that the introduction of both

4 nitrogen and phosphorus penalties at a high level led to larger reductions

5 of nitrogen and phosphorus excretions compared with the unilateral

6 introduction of nitrogen or phosphorus penalty.

7

3.5.Influence of the substitution rate of food by-products for concentrates

and price levels of concentrates on the replacement price of food by-products

Table 5 shows the replacement price of food by-products under different substitution rates and concentrate prices. The result clearly demonstrates the positive relationship between the replacement price of food by-products and the concentrate price levels and the negative relationship between the replacement price of food by-products and the substitution rates of food by-products for concentrates.

\section{Discussion}

4.1.Reduction of phosphorus excretion with the use of food by-products

Nitrogen excretion was increased by the use of food by-products

22 because of higher CP contents of food by-products selected in this study

23 than those of concentrates, but phosphorus excretion was strongly

24 decreased with the use of food by-products (Fig. 3). In the ration

25 formulation with only concentrates, the proportion of wheat bran was 
approximately the upper bound of the feeding limit. Because wheat bran

4.2. Changes in feed ingredients selected by the feed formulation under the three penalty levels

The proportion of soybean curd residue was the highest when no penalties were introduced (Table 4). Cao et al. (2009) reported that the addition of dried soybean curd residue to TMR silage increased the fermentation quality and resulted in high nutrient digestibility. Moreover, in a later study, Cao et al., (2010) reported that fermented TMR increased digestibility, decreased methane emissions which might be caused by the conversion of lactic acid to propionic acid in the rumen, and resulted in a lower loss of energy as methane compared to non-fermented TMR. In consideration of this finding as well as the present simulation, the inclusion of soybean curd residue in fermented TMR is a suitable solution both from a nutritional and environmental point of view.

However, the proportion of soybean curd residue decreased but that of udon noodle waste increased consistently with the penalty levels. This was attributable to the fact that the udon noodle waste had low CP and high TDN contents while the soybean curd residue had high CP and high 
1 TDN contents. However, Maghsoud et al. (2008) reported that noodle waste degraded rapidly because of its high level of starch, and Wang et al. (2009) mentioned that high dietary starch resulted in a decrease in ruminal pH and that subacute ruminal acidosis can occur when the pH decreases dramatically. Adding some constrained parameters associated with ruminal fermentation characteristics in the feed formulation may improve the result of formulation.

Brewer's grain has considerable potential as a feed for growing and finishing cattle because of its high energy and high CP and apparent roughage characteristics (Preston et al. 1973). However, brewer's grain was not selected as a food by-product ingredient in the optimal ration. This may have been due to the low TDN content per DM of brewer's grain compared to that of soybean curd residue.

In the ingredients of concentrates, the proportion of barley was increased but that of wheat bran was decreased in keeping with the penalty levels. It is known that wheat bran is a generally suitable feed resource for beef cattle because of its degradable fiber content and relatively low price compared to other concentrates. Furthermore, an amount of wheat bran less than that isocaloric to corn may provide a similar production response due to a lessening of the negative associative effects on forage intake and digestibility (Hess et al., 1996). Nevertheless, the introduction of penalties reduced the content of wheat bran in the optimal rations because of its high phosphorus content, and resulted in a switch from wheat bran to barley as an alternative resource of protein and fiber. 


\subsection{Importance of introducing both nitrogen and phosphorus penalties}

In the simulation for a beef cattle production using whole crop rice silage, Hirooka and Oishi (2010) stated that the introduction of a penalty for nitrogen excretion lead to a simultaneous reduction in phosphorus excretion. Jean dit Bailleul et al. (2001) and Pomar et al. (2007) also used the feed formulation method for pig production including only nitrogen penalty or phosphorus penalty. The results of the present study shown in Fig.5, however, indicated that the introduction of both nitrogen and phosphorus penalties could have a synergistic effect on the reduction of nitrogen and phosphorus excretions; in other words, the introduction of the nitrogen penalty did not result in a satisfactory reduction of phosphorus excretion and vice versa.

4.4. Replacement price levels of food by-products associated with the substitution rate of food by-products for concentrates and price levels of concentrates

The replacement price of food by-products was positively related with the concentrate price levels and negatively related with the substitution rates of food by-products for concentrates (Table 5). The positive relationship between the replacement price of food by-products and the concentrate price levels was expected, because the concentrate prices may compete with the food by-product prices, and thereby increases in the former could lead to increases in the latter. Meanwhile, the negative relationship between the replacement price of food by-products and the 
1 substitution rates of food by-products for concentrates might indicate that a large quantity of food by-products with high water content should be required to replace the full amount of nutrients in concentrates.

The average replacement price of food by-products at all price levels and substitution rates in Table 5 was 17.3 (yen/kg), which was about $37 \%$ of the average price of concentrates ( 46.8 yen/kg). This may be because a high level of food by-products is needed to substitute for concentrates due to their low DM content. Therefore, if the total cost for transport and conservation of food by-products is about 11 (yen/kg) on an as-fed basis in Japan, as reported by Kajikawa (1996), the food by-products should be supplied at a very low price (6.3 yen/kg) from waste managers. Nevertheless, the use of food by-products would be supported by the public because it can help waste managers solve the economic and environmental problems of waste disposal.

\subsection{Applicability of the feed formulation method}

The optimization of multiple criteria pertaining to feed formulation, such as minimization of feed cost and environmental load, has generally been carried out using multi-objective models (Tozer and Stokes, 2001; Giasson et al., 2002; Castrodeza et al., 2005). However, it is often difficult to find a solution using multi-objective models. In addition, these models are technically complicated, and their use requires specific computation skills or specialized software. In contrast, the least-cost ration formulation method with the introduction of nitrogen and phosphorus penalty coefficients used in the present study represents a 
1 simple modification of the traditional linear programming and can be

2 easily and widely applied to various feeding conditions. Numerous

3 by-products, including food, agricultural, and industrial by-products,

4 have potential for use as animal feeds, but their availability varies

5 enormously among regions and their nutritional values also vary

6 depending on the conditions of the local production systems. To account

7 for the regional differences in feed availability, Grasser et al. (1995)

8 formulated rations including different combinations of nine by-products

9 like brewer's grain and citrus pulp for dairy productions in three regions

10 in California. Therefore, the wide availability of the feed formulation

11 method can allow livestock producers to utilize economically and

12 environmentally effective by-products as local feed resources.

4.6.Implication of the use of food by-products as feeds in beef production

At present, by-product feedstuffs constitute a significant portion of the feedstuffs in animal industries and a beneficial resource that can be converted by ruminants into animal products that otherwise would need to

18 be disposed of (Grasser et al., 1995). Agricultural and food by-products

19 could substantially contribute to the feed supply and release the pressures

20 on agricultural land use (Steinfeld et al., 2006 ). Therefore, by-product

21 feedstuffs are no longer considered food waste by-products but rather

22 normal commodities to be incorporated into a commercial feeding program

23 (Westendorf, 2000 ). However, it should be noted that some problems still

24 exist in the use of food by-products. One important problem to be solved

25 is the high nutritional variability of food by-products, which is caused by 
1 differences in season, region, processing, etc. Moreover, one concern

2 with the use of food by-products might remain, especially for the beef

3 production system: the beef quality. In fact, a negative relationship

4 between the proportion of by-products in diets and carcass quality of

5 culled animals has been reported (Harpster, 2000 ; Bampidis and Robinson,

62006 ; Sugimoto et al., 2009). Therefore, further investigations will be

7 needed to identify measures for improving the quality control of food

8 by-products and the beef produced using them, as well as additional

9 factors that might be constrained in the feed formulations. These

10 investigations will promote economically and environmentally efficient

11 utilization of the food by-products in beef production systems.

\section{Conclusions}

This study demonstrated the application of the modified least-cost feed

16 formulation to the beef fattening production system using food by-products, while introducing the penalty costs for nitrogen and

18 phosphorus excretions. Analyses of the price of food by-products

19 indicated that the replacement price was not greatly affected by the

20 change in the penalty level. The nitrogen and phosphorus penalties

21 greatly changed the feed composition and reduced the excretions,

22 indicating the importance of introducing both penalty coefficients to the

23 objective function for effective reduction of both excretions in animal

24 productions. These analyses showed the simplicity and efficacy of the

25 modified least-cost feed formulation method for determining 
economically and environmentally optimal rations using various feed resources.

\section{References}

Bampidis, V.A., Robinson, P.H., 2006. Citrus by-products as ruminant feeds: A review. Anim. Feed Sci. Technol. 128, 175-217.

Brokken, R.F. 1971., Programming models for use of the Lofgreen-Garrett net energy system in formulating rations for beef cattle. J. Anim. Sci. 32, 685-691.

Cao, Y., Takahashi, T., Horiguchi, K., 2009. Effects of addition of food by-products on the fermentation quality of a total mixed ration with whole crop rice and its digestibility, performance, and rumen fermentation in sheep. Anim. Feed Sci. Technol. 151, 1-11.

Cao, Y., Takahashi, T., Horiguchi, K. Yoshida, N., Cai, Y., 2010. Methane emissions from sheep fed fermented or non-fermented total mixed ration containing whole-crop rice and rice bran. Anim. Feed Sci. Technol. 157, $72-78$.

Castrodeza, C., Lara, P., Peña, T., 2005 . Multicriteria fractional model for feed formulation: economic, nutritional and environmental criteria. Agric. Sys. 86, 76-96.

Crabtree, J.R., 1982. Interactive formulation system for cattle diets. Agric. Sys. 8, 291-308.

Giasson, E., Bryant, R.B., Bills, N.L., 2002. Environmental and economic optimization of dairy manure management. Agron. J. 94, 757-766. 
Grasser, L.A., Fadel, J.G., Garnett, I., DePeters, E.J., 1995. Quantity and economic importance of nine selected by-products used in California dairy rations. J. Dairy Sci. 78, 962-971.

Hanegraaf, M.C., den Boer, D.J., 2003. Perspectives and limitations of the Dutch mineral accounting system (MINAS). Eur. J. Agron. 20, $25-31$.

Harpster, H.W., 2000. Case studies in utilizing food-processing by-products as cattle and hog feed, in: Westendorf, M.L. ( $1^{\text {st }}$ Eds.), Food Waste to Animal Feed. Iowa State University Press, Ames, Iowa, pp.145-162.

Hess, B.W., Krysl, L.J., Judkins, M.B., Holcombe, D.W., Hess, J.D., Hanks, D.R., Huber, S.A., 1996. Supplemental cracked corn or wheat bran for steers grazing endophyte-free fescue pasture: effects on live weight gain, nutrient quality, forage intake, particulate and fluid kinetics, ruminal fermentation, and digestion. J. Anim. Sci. 74, $1116-1125$.

Hirooka, H., Oishi, K., 2010. Least cost ration formulation with whole crop rice silage for beef cattle feedlot production. Nihon Chikusan Gakkaiho 81,333-343. (in Japanese with English Abstr.)

Jean dit Bailleul, P., Rivest, J., Dubeau, F., Pomar, C., 2001 . Reducing nitrogen excretion in pigs by modifying the traditional least-cost formulation algorithm. Livest. Prod. Sci. 72, 199-211.

Kajikawa, H., 1996. Utilization of by-products from food processing as livestock feed in Japan. Extension Bulletins of Food and Fertilizer Technology Center, Taipei. pp.1-8. 
1 Kikuhara, K., Kumagai, H., Hirooka, H., 2009. Development and evaluation of a simulation model for dairy cattle production systems integrated with forage crop production. Asian-Australasian J. Anim. Sci. 22, 57-71.

Maghsoud, B., Akbar, T., Hossein, J., Ali, M.G., 2008 . Evaluation of some by-products using In situ and In vitro gas production techniques. Am. J. Anim. and Vet. Sci. 3, 7-12.

Ministry of Agriculture, Forestry and Fisheries (MAFF)., 2006 . Statistics for Prices of Materials for Agricultural Production. Ministry of Agriculture, Forestry and Fisheries, Tokyo. (in Japanese)

Ministry of Agriculture, Forestry and Fisheries (MAFF)., 2010. Statistics for Prices of Materials for Agricultural Production. Ministry of Agriculture, Forestry and Fisheries, Tokyo. (in Japanese)

National Agricultural and Food Research Organization (NARO)., 2008. Japanese Feeding Standard for Beef Cattle. National Agricultural and Food Research Organization, Japan Livestock Industry Association, Tokyo. (in Japanese)

National Agricultural and Food Research Organization (NARO)., 2009. Standard Tables of Feed Composition in Japan. National Agricultural and Food Research Organization, Japan Livestock Industry Association, Tokyo. (in Japanese)

NRC., 2000 . Nutrient Requirements of beef cattle. Update 2000. National Academic Press, Washington DC.

Ogino, A., Kaku, K., Osada, T., Shimada, K., 2004 . Environmental impacts of the Japanese beef-fattening system with different 
feeding lengths as evaluated by a life-cycle assessment method. J. Anim. Sci. 82, 2115-2122.

Ogino, A., Orito, H., Shimada, K, Hirooka, H., 2007. Evaluating environmental impacts of the Japanese beef cow-calf system by the life cycle assessment method. Anim. Sci. J. 78, 424-432.

Oka, A., Maruo, Y., Miki, T., Yamasaki, T., Saito, T., 1998. Influence of vitamin A on the quality of beef from the Tajima strain of Japanese Black cattle. Meat Sci. 48, 159-167.

Pomar, C., Dubeau, F., Létourneau-Montminy, M.P., Boucher, C., Julien, P.O., 2007. Reducing phosphorus concentration in pig diets by adding an environmental objective to the traditional feed formulation algorithm. Livest. Sci. 111, 16-27.

Preston, R.L., Vance, R.D., Cahill, V.R., 1973. Evaluation of brewers grains for growing and finishing cattle. J. Anim.Sci. 37: 174-178.

Steinfeld, H., Gerber, P., Wassenaar, T.D., Castel, V., Rosales, M., de Haan, C., 2006. 2.3 Geography of livestock resources, in: Livestock's long shadow: environmental issues and options. The Livestock, Environment and Development (LEAD), Food and Agriculture Organization of the United Nations (FAO), Rome, pp. $34-49$.

Sugimoto, M., Saito, W., Ooi, M., Sato, Y., Saito, T., 2009 . The effects of inclusion levels of urea-treated potato pulp silage in concentrate and roughage sources on finishing performance and carcass quality in cull beef cows. Anim. Sci.J. 80, 280-285.

Sugiura, K., Yamatani, S., Watahara, M., Onodera, T., 2009. Ecofeed, 
animal feed produced recycle food waste. Veterinaria Italiana 45, $397-404$.

Swain, S.M, Armentano, L.E. 1994. Quantitative evaluation of fiber from nonforage sources used to replace alfalfa silage. J. Dairy Sci. 77, $2318-2331$

Tamminga, S., 1992. Nutrition management of dairy cows as a contribution to pollution control. J. Dairy Sci. 75, 345-357.

Tedeschi, L.O., Fox, D.G., Chase, L.E., Wang, S.J., 2000 . Whole-herd optimization with the Cornell Net Carbohydrate and Protein system. I. Predicting feed biological values for diet optimization with linear programming. J. Dairy Sci. 83, 2139-2148.

Tozer, P.R., 2000. Least-cost ration formulations for Holstein dairy heifers by using linear and stochastic programming. J. Dairy Sci. $83,443-451$.

Tozer, P.R., Stokes, J.R., 2001. A multi-objective programming approach to feed ration balancing and nutrient management. Agric. Sys. 67, $201-215$

Visual Numerics, Inc., 1994. IMSL Math/Library, FORTRAN Subroutines for Mathematical Applications, Volume 2. Houston.

Wang, Y.H., Xu, M., Wang, F.N., Yu, Z.P., Yao, J.H., Zan, L.S., Yang, F.X., 2009. Effect of dietary starch on rumen and small intestine morphology and digesta pH in goats. Livest. Sci. 122, 48-52.

Westendorf, M.L., 2000. Food waste as animal feed: an introduction, in:

Westendorf, M.L. ( $1^{\text {st }}$ Eds.), Food Waste to Animal Feed. Iowa State University Press, Ames, Iowa, pp.3-15. 


\section{Appendix}

1. Estimation of the Gompertz growth curve parameters using average 5 daily gain

6

7 The Gompertz growth curve function is expressed as:

$$
W_{t}=A e^{-B e^{-k t}}
$$

8 where $W_{t}$ (kg) is the body weight at age $t$ (days), the parameter $A$ is

9 mature weight, the parameter $B$ is the constant of integration and the

10 parameter $k$ is the maturing rate. The function (A.1) can be transformed 11 a s :

$$
-B e^{-k t}=\log \left(W_{t} / A\right)
$$

12 When the start days $t_{s}$ and final days $t_{f}$ of fattening and the start

13 weight $W_{s}$ and the final weight $W_{f}$ are provided, then the following 14 expressions are obtained:

$$
\begin{aligned}
& -B e^{-k t_{s}}=\log \left(W_{s} / A\right) \\
& -B e^{-k t_{f}}=\log \left(W_{f} / A\right) .
\end{aligned}
$$

15 Dividing (A.3) by (A.4) and logarithmically transforming both sides leads 16 to the following function (A.5) for solving the parameter $k$ :

$$
k=\frac{\log \left\{\log \left(W_{s} / A\right) / \log \left(W_{f} / A\right)\right\}}{t_{f}-t_{s}} .
$$

17 Next, the average daily gain ( $A D G$ ) for the entire fattening period is 18 determined as: 


$$
A D G=\frac{W_{f}-W_{s}}{t_{f}-t_{s}}
$$

1 and the function (A.5) can be expressed by $A D G$ as:

$$
k=\frac{\log \left\{\log \left(W_{s} / A\right) / \log \left(W_{f} / A\right)\right\}}{\left(W_{f}-W_{s}\right) / A D G} .
$$

2 Thus, we can calculate the parameter $k$ by the expression (A.7) when the 3 parameters $A, W_{s}, \quad W_{f}$ and $A D G$ are provided, and we can then 4 calculate the parameter $B$ by the calculated parameter $k$ and the given 5 parameter $t_{s}$ by the expression (A.3).

6 Finally, the daily gain $D G_{t}$ (kg) at age $t$ (days) by the Gompertz growth

7 function is expressed using the calculated growth parameter $k$ and the 8 mature weight $A$ as:

$$
D G_{t}=k W_{t} \log \left(A / W_{t}\right)
$$

9

102 . Setting constrained values for restriction of the feeding amount in

11 linear programming

13 For example, when the upper bound for the ratio of the feeding amount of 14 wheat bran ( $B)$ to concentrates ( $B+C: C$ is the total feeding amount of 15 other concentrates) is set to be $25 \%$, the relationship between $B$ and $C$ 16 is :

$$
B \leq 0.25(B+C)
$$

17 Therefore, the following inequality constraint is specified and the 18 coefficients become the constrained values shown in Table 2:

$$
0.25 C-0.75 B \geq 0 \text {. }
$$


Table 1

Composition of ingredients ${ }^{1)}$ and the ingredient prices $^{2)}$ used in this study

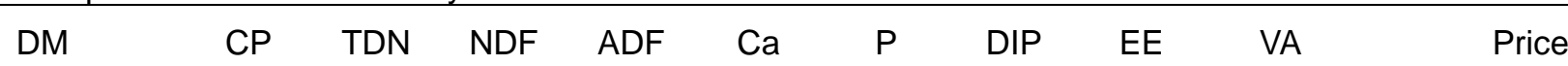

g/kg, as-fed basis g/kgDM g/kgDM g/kgDM g/kgDM g/kgDM g/kgDM g/gCP g/kgDM IU/kgDM yen ${ }^{3} / \mathrm{kg}$, as-fed basis

Food by-products: Eco

1 Brewer's grain (wet)

2 Soybean curd residue (wet)

$\begin{array}{rrrr}277 & 249 & 722 & 269 \\ 225 & 262 & 911 & 135 \\ 660 & 277 & 791 & 140 \\ 732 & 131 & 706 & 0 \\ 252 & 131 & 810 & 05 \\ 200 & 210 & 465 & 238\end{array}$

$\begin{array}{rrrr}97 & 2.9 & 6.1 & 0.594 \\ 89 & 3.8 & 3.6 & 0.695 \\ 98 & 4.8 & 1.6 & 0.858 \\ 0 & 11.8 & 1.1 & 0.930 \\ 3 & 0 & 0.8 & 0.852 \\ 174 & 8.0 & 2.5 & 0.114\end{array}$

$\begin{array}{rrl}101 & 0 & \text { variable } \\ 115 & 0 & \text { variable } \\ 166 & 0 & \text { variable } \\ 9 & 0 & \text { variable } \\ 19 & 0 & \text { variable } \\ 186 & 2510 & \text { variable }\end{array}$

Purchased concentrates: Con

\begin{tabular}{|c|c|c|c|c|c|c|c|c|c|c|c|}
\hline 1 Calcium carbonate & 996 & 0 & 0 & 0 & 0 & 388.9 & 0.1 & 0 & 0 & 0 & 60.0 \\
\hline 2 Corn & 855 & 89 & 936 & 36 & 20 & 0.3 & 3.0 & 0.605 & 44 & 2000 & $40.1(32.5,59.2)$ \\
\hline 3Barley & 885 & 120 & 841 & 227 & 67 & 0.6 & 3.7 & 0.850 & 24 & 0 & $49.1(41.0,73.8)$ \\
\hline 4 Soybean meal & 882 & 510 & 871 & 155 & 96 & 3.7 & 7.2 & 0.740 & 22 & 0 & $65.3(56.7,87.4)$ \\
\hline 5 Wheat bran & 868 & 181 & 722 & 426 & 141 & 1.2 & 11.4 & 0.822 & 49 & 0 & $32.7(27.5,42.9)$ \\
\hline \multicolumn{12}{|l|}{ Roughages: Rou } \\
\hline 1 Hay $^{4)}$ & 851 & 114 & 617 & 645 & 394 & 4.7 & 2.8 & 0.705 & 34 & 11000 & 54.9 \\
\hline 2Rice straw & 878 & 54 & 428 & 631 & 392 & 3.0 & 1.3 & 0.490 & 21 & 1200 & 36.0 \\
\hline
\end{tabular}

1) National Agriculture and Food Research Organization (2009): DM, CP, TDN, NDF, ADF, CA, P, DIP, EE and VA are total dry matter, crude protein, total digestible nutrients, neutral detergent fiber, acid detergent fiber, calcium, phosphorus, degradable intake protein, ether extract and total vitamin A, respectively.

2) Ministry of Agriculture, Forestry and Fisheries (2006, 2010): the prices of food by-products are variable between 1 and 30, the prices for concentrates and roughages are average values in 9 years (from 2000 to 2009) and the prices in parentheses for concentrates indicate the lowest (left) and the highest (right) prices in the 9 years.

3) 1 euro $=120$ yen

${ }^{4)}$ Includes Italian ryegrass hay, timothy hay and orchardgrass hay, based on Ogino et al. (2004). 
Table 2

Table representing the coefficient_matrix $\boldsymbol{A}$ and the vector of nutrient requirements and constraints $\boldsymbol{B}$ for the least-cost feed formulation for the production in which food by-products were used in this study ${ }^{1)}$

\begin{tabular}{|c|c|c|c|c|c|c|c|c|c|c|c|c|c|c|c|}
\hline & Eco1 & Eco2 & Eco3 & Eco4 & Eco5 & Eco6 & Con1 & Con2 & Con3 & Con4 & Con5 & Rou1 & Rou2 & & Constraint $^{2)}$ \\
\hline \multicolumn{16}{|l|}{ Limitation for nutrient requirements } \\
\hline DM & 0.277 & 0.225 & 0.660 & 0.732 & 0.252 & 0.200 & 0.996 & 0.855 & 0.885 & 0.882 & 0.868 & 0.851 & 0.878 & $=$ & DMReq \\
\hline $\mathrm{CP}$ & 0.069 & 0.059 & 0.183 & 0.096 & 0.033 & 0.042 & 0 & 0.076 & 0.106 & 0.450 & 0.157 & 0.097 & 0.047 & $\geq$ & CPReq \\
\hline TDN & 0.200 & 0.205 & 0.522 & 0.517 & 0.204 & 0.093 & 0 & 0.800 & 0.744 & 0.768 & 0.627 & 0.525 & 0.376 & $\geq$ & TDNReq \\
\hline NDF & 0.074 & 0.030 & 0.092 & 0 & 0.001 & 0.048 & 0 & 0.031 & 0.201 & 0.137 & 0.370 & 0.549 & 0.554 & $\geq$ & 0.16DMReq \\
\hline ADF & 0.027 & 0.020 & 0.064 & 0 & 0.001 & 0.035 & 0 & 0.017 & 0.059 & 0.085 & 0.122 & 0.335 & 0.344 & $\geq$ & 0.10DMReq \\
\hline $\mathrm{Ca}$ & 0.0008 & 0.0009 & 0.0032 & 0.0087 & 0 & 0.0016 & 0.3873 & 0.0003 & 0.0005 & 0.0033 & 0.0010 & 0.0040 & 0.0026 & $\geq$ & CaReq \\
\hline$P$ & 0.0017 & 0.0008 & 0.0011 & 0.0008 & 0.0002 & 0.0005 & 0.0001 & 0.0026 & 0.0033 & 0.0064 & 0.0099 & 0.0024 & 0.0011 & $\geq$ & PReq \\
\hline Ca:P balance (lower limit) & -0.0017 & -0.0004 & 0.0016 & 0.0075 & -0.0003 & 0.0009 & 0.3872 & -0.0036 & -0.0044 & -0.0063 & -0.0138 & 0.0004 & 0.0009 & $\geq$ & $0(\mathrm{Ca} / \mathrm{P}=1.5)$ \\
\hline Ca:P balance (upper limit) & -0.0025 & -0.0008 & 0.0011 & 0.0071 & -0.0004 & 0.0006 & 0.3871 & -0.0049 & -0.0060 & -0.0094 & -0.0187 & -0.0007 & 0.0004 & $\leq$ & $0(\mathrm{Ca} / \mathrm{P}=2.0)$ \\
\hline DIP & 0.041 & 0.041 & 0.157 & 0.089 & 0.028 & 0.005 & 0 & 0.046 & 0.090 & 0.333 & 0.129 & 0.068 & 0.023 & $\geq$ & DIPReq \\
\hline EE & 0.028 & 0.026 & 0.109 & 0.001 & 0.006 & 0.011 & 0 & 0.038 & 0.021 & 0.019 & 0.043 & 0.025 & 0.018 & $\leq$ & 0.06DMReq \\
\hline VA (lower limit) & 0 & 0 & 0 & 0 & 0 & 12550 & 0 & 2339 & 0 & 0 & 0 & 12926 & 1367 & $\geq$ & VAReq \\
\hline VA (upper limit) & 0 & 0 & 0 & 0 & 0 & 12550 & 0 & 2339 & 0 & 0 & 0 & 12926 & 1367 & $\leq$ & VAReq+3000 \\
\hline \multicolumn{16}{|l|}{ Limitation for amount of feeds } \\
\hline Roughage & 0 & 0 & 0 & 0 & 0 & 0 & 0 & 0 & 0 & 0 & 0 & 0.851 & 0.878 & $\geq$ & $\mathrm{RR}$ \\
\hline Wheat bran in concentrates & 0.25 & 0.25 & 0.25 & 0.25 & 0.25 & 0.25 & 0.25 & 0.25 & 0.25 & 0.25 & -0.75 & 0 & 0 & & 0 \\
\hline Water content & -0.073 & -0.125 & 0.310 & 0.382 & -0.098 & -0.150 & 0.646 & 0.505 & 0.535 & 0.532 & 0.518 & 0.501 & 0.528 & $\geq$ & 0 (65\%water) \\
\hline Soy sauce cake & 0 & 0 & 0.08 & 0 & 0 & 0 & 0 & 0 & 0 & 0 & 0 & 0 & 0 & $\leq$ & 0.01DMReq \\
\hline Blackstrap molasses & 0 & 0 & 0 & 1 & 0 & 0 & 0 & 0 & 0 & 0 & 0 & 0 & 0 & $\leq$ & 0.4 \\
\hline Green tea waste & 0 & 0 & 0 & 0 & 0 & 0.200 & 0 & 0 & 0 & 0 & 0 & 0 & 0 & $\leq$ & 0.15DMReq \\
\hline $\begin{array}{l}\text { Substitution rate of food } \\
\text { by-products for concentrates }\end{array}$ & $-\left(1-S^{3} b^{3)}\right)$ & $-(1-S u b)$ & -(1-Sub) & $-(1-S u b)$ & $-(1-S u b)$ & $-(1-S u b)$ & Sub & Sub & Sub & Sub & Sub & 0 & 0 & 3 & 0 \\
\hline
\end{tabular}

${ }^{1)}$ Eco1: Brewer's grain (wet), Eco 2: Soybean curd residue (wet), Eco3: Soy sauce cake (wet), Eco 4: Blackstrap molasses, Eco 5: Udon noodle waste, Eco 6: Green tea waste, Con1: Calcium carbonate, Con2: Corn, Con3: Barley, Con 4: Soybean meal, Con5: Wheat bran, Rou1: Hay, Rou2: Rice straw

2) Req, such as "DMReq", indicates nutrition requirement including 10\% safety margin and RR means lower boundary of roughage ratio (/kgDM).

3) Sub indicates substitution rate of concentrates for food by-products. 


\section{Table 3}

Base condition and the alternatives in simulation

\begin{tabular}{|c|c|}
\hline Simulation conditions & Base and the alternatives \\
\hline \multicolumn{2}{|c|}{ Nitrogen and phosphorus penalty } \\
\hline No penalty & 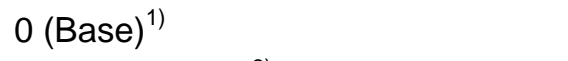 \\
\hline Penalty $x 1^{2)}$ & $\mathrm{N}: 2.30$ euro/ $\mathrm{kg}^{3)}, \mathrm{P}: 3.92$ euro/kg \\
\hline Penalty x2 & $\mathrm{N}: 4.60$ euro/kg, P: 7.84 euro/kg \\
\hline \multicolumn{2}{|l|}{ Substitution rate of food } \\
\hline Low & $\underline{0.25}$ \\
\hline Middle & $\underline{0.50 \text { (Base) }}$ \\
\hline High & $\underline{0.75}$ \\
\hline \multicolumn{2}{|c|}{ Price level of concentrates ${ }^{4)}$} \\
\hline Low & $32.5,41.0,56.7,27.5 \mathrm{yen}^{3)} / \mathrm{kg}$ \\
\hline Average & $40.1,49.1,65.3,32.7$ yen/kg (Base) \\
\hline High & $59.2,73.8,87.4,42.9$ yen $/ \mathrm{kg}$ \\
\hline \multicolumn{2}{|l|}{ 1) Base situation } \\
\hline \multicolumn{2}{|c|}{ 2) Derived from Hanegraaf and den Boer (2003) } \\
\hline \multicolumn{2}{|l|}{ 3) 1 euro $=120$ yen } \\
\hline 4) also see Table 1 & \\
\hline
\end{tabular}




\section{Table 4}

Optimum rations, feed costs and nitrogen and phosphorus excretions under three penalty conditions, when the price of food by products was set to be $16\left(\right.$ yen $^{1} / \mathrm{kg}$, as-fed basis)

\begin{tabular}{|c|c|c|c|c|c|c|c|c|c|c|c|c|c|c|c|c|c|}
\hline \multirow[t]{2}{*}{ Penalty $^{2)}$} & \multirow[t]{2}{*}{ Period $^{3)}$} & \multicolumn{13}{|c|}{ Feed composition ${ }^{4)}(\mathrm{kg} / \mathrm{kg}$ in total feed amount, as-fed basis) } & \multirow{2}{*}{$\begin{array}{c}\text { Feed } \\
\text { cost } \\
\text { (yen) }\end{array}$} & \multicolumn{2}{|c|}{ Excretion } \\
\hline & & Eco1 & Eco2 & Eco3 & Eco4 & Eco5 & Eco6 & Con1 & Con2 & Con3 & Con4 & Con5 & Rou1 & Rou2 & & $\begin{array}{c}\mathrm{N} \\
(\mathrm{kg})\end{array}$ & $\begin{array}{c}\mathrm{P} \\
(\mathrm{kg})\end{array}$ \\
\hline \multirow[t]{4}{*}{0} & 1 & 0 & 24.27 & 7.64 & 2.79 & 0 & 6.24 & 0.46 & 32.65 & 0 & 0 & 7.82 & 0 & 18.14 & 87232 & 32.87 & 5.11 \\
\hline & 2 & 0 & 35.50 & 7.42 & 2.99 & 0 & 0 & 0.75 & 14.40 & 16.78 & 0 & 13.98 & 0 & 8.18 & 78422 & 38.25 & 7.44 \\
\hline & 3 & 0 & 33.14 & 7.63 & 3.47 & 1.48 & 0 & 0.86 & 24.69 & 0 & 0 & 20.16 & 0 & 8.58 & 63807 & 31.65 & 6.08 \\
\hline & Total & 0 & 30.97 & 7.56 & 3.08 & 0.49 & 2.08 & 0.69 & 23.91 & 5.59 & 0 & 13.99 & 0 & 11.63 & 229460 & 102.77 & 18.63 \\
\hline \multirow[t]{4}{*}{1} & 1 & 0 & 24.27 & 7.64 & 2.79 & 0 & 6.24 & 0.46 & 32.65 & 0 & 0 & 7.82 & 0 & D 18.14 & 87228 & 31.84 & 4.97 \\
\hline & 2 & 0 & 4.32 & 7.54 & 3.04 & 30.94 & 0 & 0.60 & 14.63 & 22.38 & 0 & 8.23 & 0 & 8.32 & 79621 & 32.88 & 5.91 \\
\hline & 3 & 0 & 0 & 7.62 & 3.47 & 34.63 & 0 & 0.86 & 24.66 & 0 & 0 & 20.20 & 0 & 8.57 & 63827 & 30.35 & 5.92 \\
\hline & Total & 0 & 9.53 & 7.60 & 3.10 & 21.85 & 2.08 & 0.64 & 23.98 & 7.46 & 0 & 12.08 & 0 & 11.67 & 230676 & 95.07 & 16.81 \\
\hline \multirow[t]{4}{*}{2} & 1 & 0 & 24.32 & 7.86 & 2.87 & 0 & 5.61 & 0.36 & 37.95 & 0 & 2.17 & 0.18 & 0 & 18.67 & 87724 & 31.84 & 4.12 \\
\hline & 2 & 0 & 0.16 & 7.61 & 3.07 & 34.40 & 0 & 0.49 & 14.12 & 26.68 & 0 & 3.96 & 0 & 9.51 & 81740 & 30.43 & 4.59 \\
\hline & 3 & 0 & 0 & 7.80 & 3.55 & 33.67 & 0 & 0.63 & 24.58 & 8.61 & 0 & 11.22 & 0 & 9.94 & 65176 & 27.60 & 5.15 \\
\hline & Total & 0 & 8.16 & 7.76 & 3.16 & 22.69 & 1.87 & 0.49 & 25.55 & 11.76 & 0.72 & 5.12 & 0 & 12.70 & 234640 & 89.88 & 13.86 \\
\hline \multicolumn{18}{|c|}{1 euro $=120$ yen } \\
\hline \multicolumn{18}{|c|}{ 2) see Table 3} \\
\hline \multicolumn{18}{|c|}{ 3) 1 : Early fattening period, 2: Middle fattening period, 3: Late fattening period } \\
\hline
\end{tabular}


Table 5

Replacement prices of food by-products ${ }^{1}$ (yen ${ }^{2} / \mathrm{kg}$, as-fed basis)

\begin{tabular}{|c|c|c|c|c|c|c|c|c|c|}
\hline $\begin{array}{l}\text { Substitution rate of } \\
\text { food by-products }\end{array}$ & & $\begin{array}{l}\text { Low } \\
(0.25) \\
\end{array}$ & & & $\begin{array}{l}\text { Middle } \\
(0.50)\end{array}$ & & & $\begin{array}{l}\text { High } \\
(0.75) \\
\end{array}$ & \\
\hline $\begin{array}{l}\text { for concentrates } \\
\text { Price level of } \\
\left.n n n n n n+r n+n n n^{3}\right)\end{array}$ & Low & Average & High & Low & Average & High & Low & Average & High \\
\hline \multicolumn{10}{|l|}{$\mathrm{N}$ and $\mathrm{P}$ penalty ${ }^{3}$} \\
\hline No penalty & 19 & 23 & 28 & 15 & 17 & 21 & 10 & 13 & 18 \\
\hline Penalty x1 & 19 & 22 & 27 & 13 & 17 & 20 & 10 & 12 & 18 \\
\hline Penalty x2 & 16 & 21 & 26 & 12 & 16 & 20 & 10 & 12 & 18 \\
\hline Mean & 18 & 22 & 27 & 13 & 17 & 20 & 10 & 12 & 18 \\
\hline
\end{tabular}

${ }^{1)}$ Maximum price of food by-products when the feed cost with the use of food by-products is below the cost without the use of food by-products.

2) 1 euro $=120$ yen

3) see Table 3 
Fig. 1. Outline of the system of feed formulation with food by-products in this study.

Fig. 2. Differences in total feed costs between the cases with and without food by-products under three nitrogen and phosphorus penalty conditions under different prices of food by-products on an as-fed basis.

Fig. 3. Differences in nitrogen and phosphorus excretions between the cases with and without the use of food by-products, when the price of food by-products was set to be 16 (yen/ $\mathrm{kg}$, as-fed basis).

Fig. 4. Effect of nitrogen and/or phosphorus penalty levels on feed costs with the use of food by-products, when the price of food by-products was set to be 16 (yen/kg, as-fed basis).

Fig. 5. Effect of nitrogen and/or phosphorus penalty levels on the reduction rates of (a) nitrogen and (b) phosphorus excretions in the production with the use of food by-products. 
1

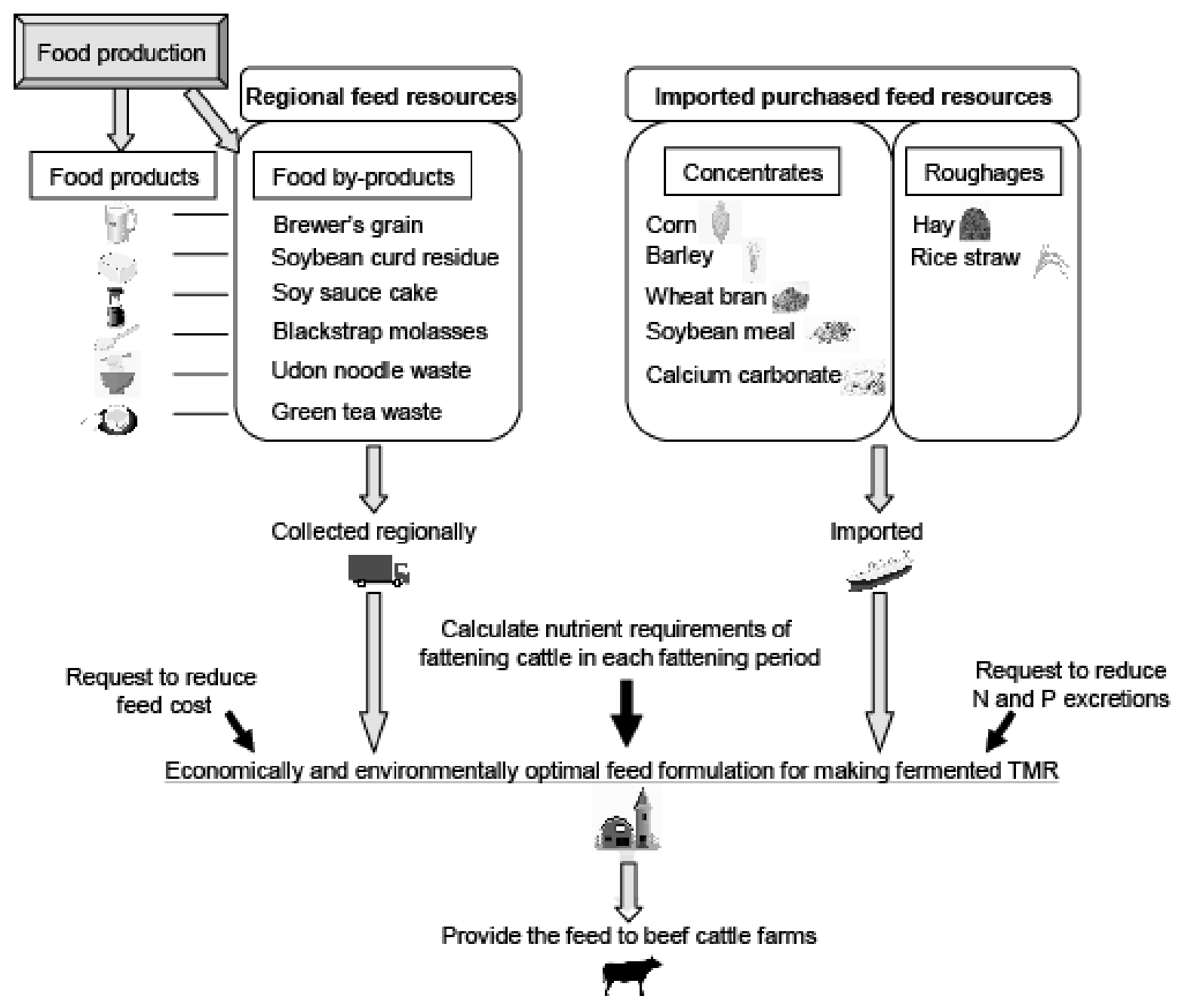

Fig. 1. Outline of the system of feed formulation with food by-products in this study 
1

2

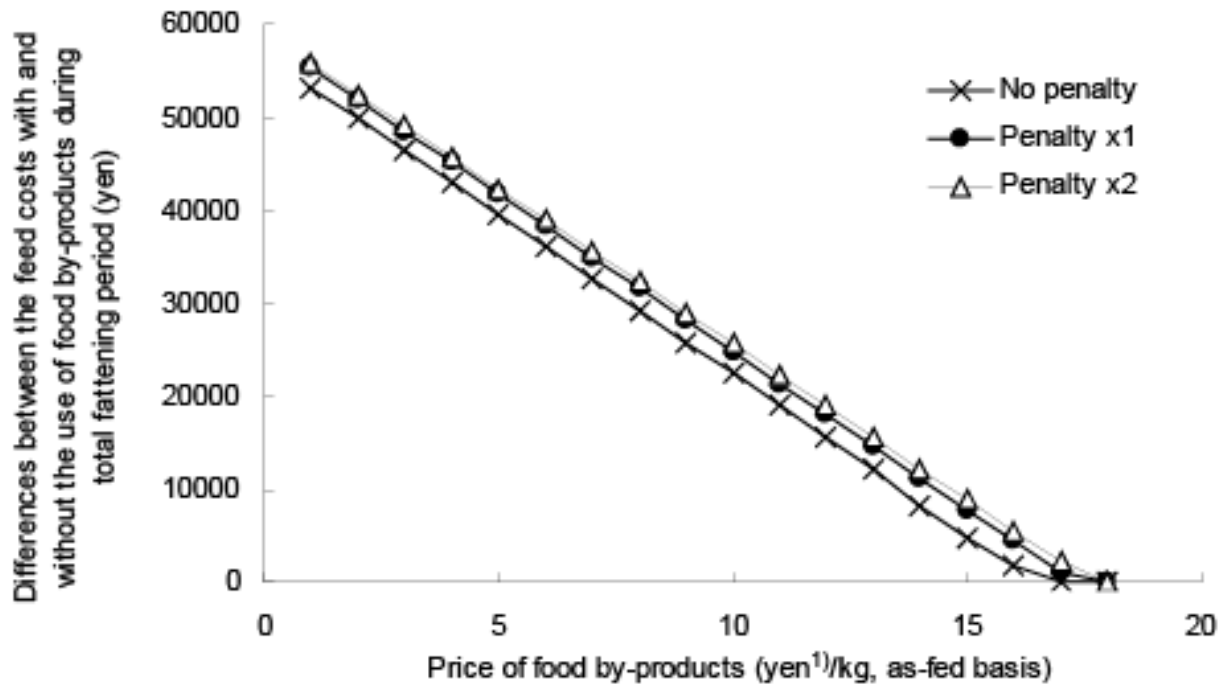

1) 1 euro $=120$ yen

Fig. 2. Differences in total feed costs between the cases with and without food by-products under three nitrogen and phosphorus penalty conditions under different prices of food by-products on an as-fed basis. 


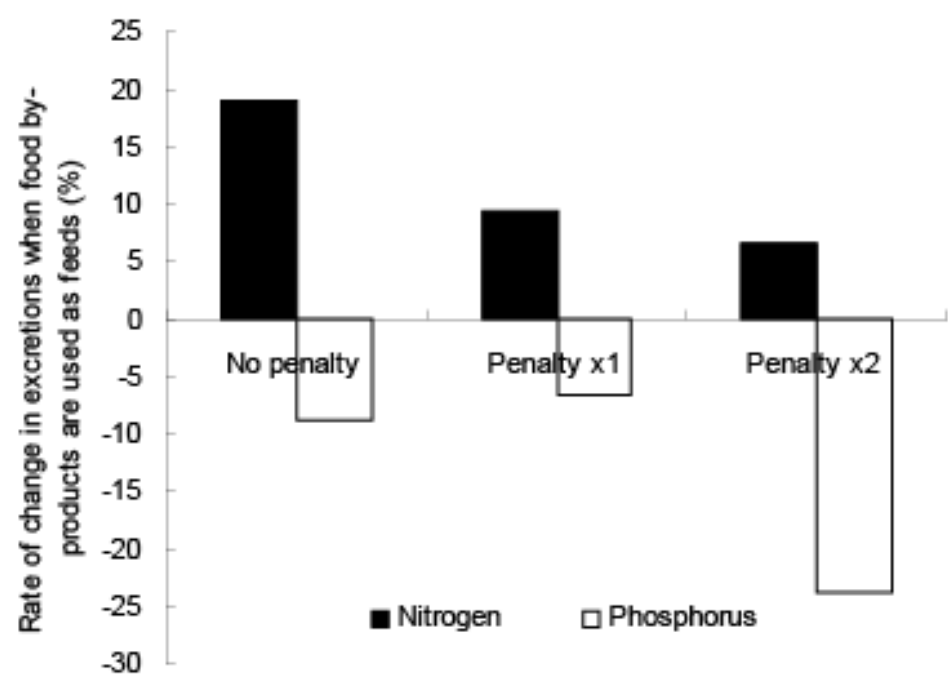

Fig. 3. Differences in nitrogen and phosphorus excretions between the cases with and without the use of food by-products , when the price of food by-products was set to be 16 (yen/kg, as-fed basis). 


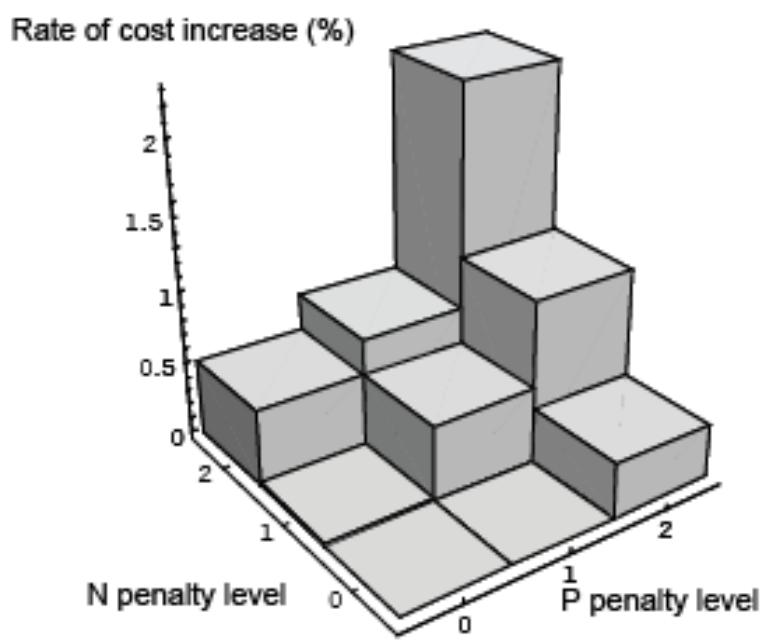

Fig. 4. Effect of nitrogen and/or phosphorus penalty levels on feed costs with the use of food by-products, when the price of food by-products was set to be 16 (yen/ $\mathrm{kg}$, as-fed basis). 
(a) Nitrogen reduction (\%)

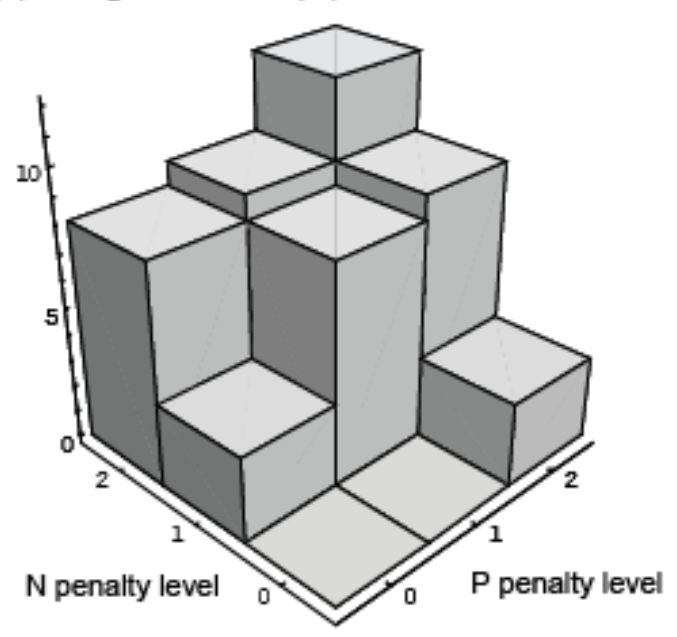

(b) Phosphorus reduction (\%)

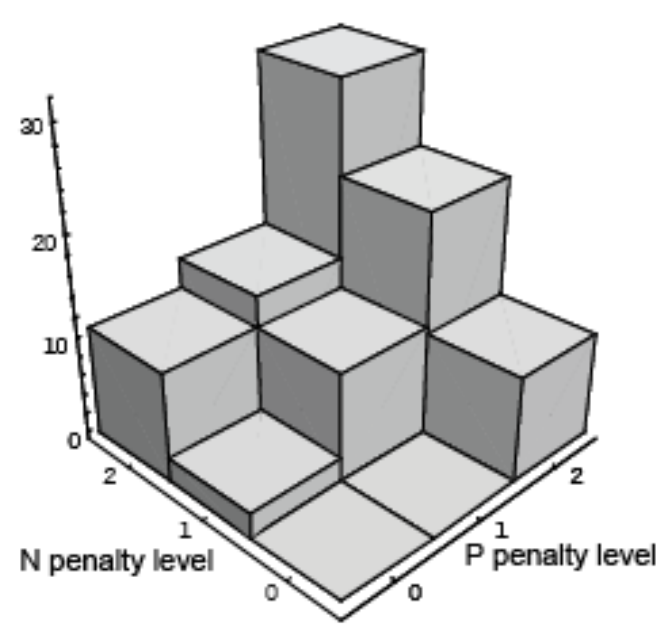

Fig. 5. Effect of nitrogen and/or phosphorus penalty levels on the reduction rates of (a) nitrogen and (b) phosphorus excretions in the production with the use of food by-products. 